\title{
Research on the Development of Intangible Cultural Heritage from the Network Perspective
}

\author{
Hongyan Song, Bin Xue, Wei Li \\ Hengshui University, Hbei, Hengshui053000 \\ hunter2011@foxmail.com
}

Keywords: New media, Intangible cultural heritage, Cultural industry, Development, Protection.

\begin{abstract}
The cultural industry in China has made great progress these years. The seventh session of the Sixth Plenary Session and eighteenth meeting provides a perfect opportunity for the development of China's cultural industry. In the process of developing cultural industry, it is crucial to pay attention to the protection of cultural content and passing on, for the reason that it is the "raw material" and "foundation" of development. The cultural industry is a "blank check" without content, which is good-looking but not working. As an important part of cultural development, intangible cultural heritage protection and exploitation is urgent, because it is not only an important source of developing cultural industry, but also a essential way to protect national culture, inherit Chinese civilization and improve the image of a country. So how to keep pace with the rapid development of new media, make protection and exploitation of intangible cultural heritage is a significant task.

According to UNESCO Convention on the Protection of Intangible Cultural Heritage, the defination of the intangible cultural heritage is as follows, "The intangible cultural heritage refers to the various groups and organizations sometimes are regarded by the individuals as all kinds of practices, performances, expression forms, knowledge systems and skills and the relevant tools, material objects, handicrafts and cultural sites. With the change of environment, and the relationship with the nature and the historical conditions the various groups and organizations constantly make the intangible cultural heritage from generation to generation get innovation, at the same time make themselves have a sense of identity and history. Thus they pomote the cultural diversity and stimulate the creativity of human beings.

With the development and popularization of new media technology, the intangible cultural heritage faces how to utilize the new medium environment to construct the platform of development opportunities. And in a sense, the survival ability of new media depends on the creation and the consumption of the "content". Therefore, grasping the development trend of new media and strongly promoting the digital content production and animation, the creation of online games will promote the development of information and cultural industries in our country to form new economic growth point.
\end{abstract}

\section{The Role of New Media in Intangible Cultural Heritage Inheritance}

Effectively Protect the Diversified Intangible Cultural Heritage Inheritance. In traditional media, the "centralization" in the communication mode makes the cultural content tend to the homogeneity and categorization. In the communication with the mainstream culture, the intangible cultural heritage with apparent local characteristics and national characteristics has always been at a disadvantage position. Therefore, it rarely appears in the mainstream media and the sight scope of the public. The communication model of new media is beyond the constraint of the mainstream discourse of mass media. Through the ways of new media, such as internets, mobile phones and so on, everyone can use the convenient way to carry on the information production and communication so as to make the different intangible cultural heritage realize the spread and development across time and space. In addition, the digital technology is widely used in the process of heritage protection, and many cultural memory has been preserved and lasted.

Implement the Industrial Value of the Topic and Creative Elements as the Cultural Content. In an age without the limitation of shelf space and other supply bottlenecks, the products 
and services which face the specific small groups have the same economic attraction with the mainstream. By the low cost advantages of storage, search, and communication, facing the personalized market demand, the new media makes those cultural products which are not popular before also have sporadic sales to make the sales be gathered into a considerable market benefits. Thus, the intangible cultural heritage as the industry value of cultural creative materials is realized.

\section{The New Model of Development with the Integration of New Media and Intangible Cultural Heritage Inheritance}

Develop the New Product Form. (1)New Products Based on the Internet. We take the portal website of intangible cultural heritage as the platform, nd use the words, pictures, audios, videos, the three-dimensional animation, and other forms of network information to provide the protection of intangible cultural heritage for the world to develop the main information of related industries, departments and units. Thus, it promotes the brand shaping and spread, makes it become the information platform for the communication and trade with the outside world and the main channel of displaying and publicizing to the outside world.

(2) New Products Based on Mobile TV. Mobile TV has wide audience, mandatory communication, the target' $\mathrm{s}$ advantage of high effective rate, and most of communication contents are the short information entertainment programs. Therefore, we should create the animation programs and video advertisments to make them be played by bus mobile TV, taxis mobile TV, subways mobile TV, buildings TV and outdoor large screen TV and other wireless digital networks. They will will have an effect of good brand image shaping and advertising communication.

(3) New Products Based on Mobilephone. The mobilephone media have the characteristics of mobility, personalization, timeliness and interactivity. audience can choose on their own, and release the information. Therefore, we should tansfer the main emphasis of product development to the content design and customer service. The production has knowledgeable, interesting and close short message quizzes, themes WAP, treasure hunting games and other contents. For example, we should take the intangible cultural heritage as the game production materials, fully excavate the cultural elements symbol, develop the heritage treasure hunting games and so on.

Create the Value Chain of New Industry. The value chain of new industry makes the intangible cultural heritage resources get the full development and utilization to brings more space for the integration of cultural industry and information industry. New media not only change the form of products, at the same time they will also penetrate in each link of new industry value chain. In the chain of new industry, it mainly includes the following links.

In the creative stage of cultural products and services, the new media take the intangible cultural heritage resources as content theme and creative elements to be able to present the design idea and product prototype with a richer form. Thus, these make them accord with the consumption demand, aesthetic taste and cultural pursuit much more.

In production stage, according to different demands of consumers, we can pass the proper new media form to bear and pass the cultural product information. For example, the cultural products which take the internet, mobile phones, mobile TV and others products as the carrier are produced.

In the distribution stage, by the new media platforms the cultural products and services from the content to the market can pass to the consumers with less costs, faster speed and more convenient way. For example, using the electronic commerce and other ways to carry on.

In consumption stage, the new media build the channel of information society. Every consumer can get to know and consume the information, products and services related to intangible cultural heritage by the platform built by the new media. The more important thing is that the new media also provide network resources and technical services for all the cultural products and cultural services purchased by the consumers.

In the development stage of derivative product, the new media provide the content copyright about the intangible cultural heritage. They use the core content to derive the products development, to extend the consumption so as to give the impetus to the development of relevant industries. 
It is important to note that because the new industry value chain is related to network operators, equipment providers, value-added service providers, content providers, new media agencies, relevant product developers and so on, the benefit game of each party and the cooperation mode all remain to get further exploration. The key thing is to strengthen division of labor and take the advantages of each other by perfecting the cooperation mechanism of the industry chain. What's more, we should adjust the interests of all parties well and make the industry get bigger and stronger together.

\section{Create New Marketing Techniques}

New media can provide rich and colorful styles for the intangible cultural heritage resources and the integrated marketing communications of products, such as issuing news reports with pictures and words, making special blogs, playing the videos on line, providing downloadable pictures and musics, launching online games, sending the advertisments and dynamic states of products to the consumers directly by e-mail or mobilephone text message and so on. What's more, aiming at some kind of intangible cultural heritage we set up the official website specially. It not only provides the relevant background introduction and production introduction of the products and other informations, but also can provide an experience service for the consumers ( such as a wonderful experience area, game park, mobile phone download area, and so on). At the same time, it is also the online channels of purchasing all kinds of derivative products. Here, advertising marketing has become the cultural experience which the audience can actively involve in. Using the advantage of word-of-mouth marketing not only makes the products and the cultural connotation get better communication, but also makes the users become the propagandist for the intangible cultural heritage consciously.

\section{Build New Profit Model}

Media Pay Model. According to the characteristics of all kinds of new media, the content providers and distributors make the creative development of the intangible cultural heritage resources to provide the users with the products and services with charge. And through the second sale, we make the attention resources of the audiences be sold to the advertisers to get the advertising revenue. Take the digital TV for example, we should take the multi-pronged approach to make the profit model roughly include the free way of participating spot commercial advertisements, the way of paying for video-on-demand without advertisements, the way of video-on-demand with clicking on advertisements for viewing time in an active way, monthly mode with low price and so on.

The Charge Mode of Value-added Service. New media platform has no physical products on sale but provides a space, and provides a service. For example, in the Internet community group of the intangible cultural heritage we can find like-minded friends or the social networks within the industry. Normally the platform registration is free. It mainly achieves the profitability by providing the value-added services and organizing some businesses and activities under the network platform.

E-business Mode. Through the trading platform provided by the new media, content providers provide the users with products, services and information related with the intangible cultural heritage to achieve profitability. The scope of business include industry product sales, derivative products sales, products auction, sales intermediary platform, franchise, member charges, Internet access, information release, and consulting services, isssuing advertisments of industry enterprises and so on.

\section{Summary}

The intangible cultural heritage protection is a long-term, arduous project. We should according to the development of The Times find the things accord with the social development needs and meet people's spiritual and cultural needs. Thus, we not only can effectively develop and utilize the 
intangible cultural heritage to give full play to its social benefits and economic benefits, but also can effectively protect and inherit the intangible cultural heritage so that it won't get the wanton destruction because of the one-sided pursuit of economic value. And the development and popularization of contemporary new media technology provides a new platform for China's intangible cultural heritage protection and development. So we should have the courage to accept it, adapt to it, and stick to do it well.

\section{Reference}

[1] Zhang micro cultural heritage protection must be reasonable use of digital technology [J], the Chinese Academy of Social Sciences, 2008, 12

[2] Zhang Naxin's traditional martial arts culture protection strategy analysis based on the intangible cultural heritage protection strategy [J], Journal of Chengdu Sport University 2010,2

[3] Mao Jingyu, Li Jiangang, et al. Research on the protection of Chinese martial arts in the perspective of intangible cultural heritage [J] Journal of Shandong Sports Institute 2009,9

[4] Zhou Jinzhang digital platform and traditional folk culture protection [J] cultural heritage 5, 2011

[5] Xu Yongjun Zhang Ying technology, culture and system: a review of the research on the digital of intangible cultural heritage [J], Zhejiang archives 2011, 6 